\title{
A Case of Subcortical Band Heterotopia Presented with Epilepsy and Speech Regression.
}

\author{
MAHMUD R ${ }^{1}$, GIAS UDDIN KMํㄹㄹ RASSEL MA ${ }^{3}$.
}

\begin{abstract}
:
Subcortical Heterotopia is a rare developmental disorder of human brain due to mutation in the DCX or LIS1gene.It is predominantly a disease of female. It usually present with refractory seizure and varying degree of mental retardation. Here a case of 22 years lady who presented with refractory seizure is reported. Her MRI revealed Double cortex and her EEG revealed Frontal intermittent rhythmic delta activity (FIRDA).
\end{abstract}

Key word: Seizure, Subcortical Band Heterotopia.

\section{Introduction:}

Subcortical Heterotopia is a rare developmental disorder of human brain. It is of three types (a) Nodular (b) Laminar and (c) subcortical band heterotopia. ${ }^{1,2}$. Subcortical band heterotopia is characterized by presence of bilaterally symmetrical, heterotopic grey matter which is located between the ventricles and the cortex ${ }^{3}$. It is the classic malformations associated with deûcient neuronal migration. ${ }^{4}$

Mutations in the DCX or LIS1gene are the predominant cause subcortical band heterotopia Altered structure or function of the proteins produced by the $D C X$ or LIS1gene impairs important interactions that are needed for neuronal migration. Without proper neuronal migration, neurons in the developing brain can be misplaced, forming abnormal bands of tissue beneath the cerebral cortex ${ }^{5,6}$.

We are going to present the first case in Bangladesh from Kamrangirchar Dhaka, who was admitted in Neurology Department, Dhaka medical college with poorly controlled seizure, speech regression and finally diagnosed as double cortex syndrome.

\section{Case report:}

Miss Shila a 22 years old lady presented with recurrent seizure since her 5 years of age. The seizure started in right hand then became generalized. The seizure persisted for 2-3 minute. There was no preceding Prodrome, aura or automatism. There was post ictal confusion but no post ictal paralysis. She also had speech regression after 2 years of the onset of seizure. She had occasional rage attack. At the time of presentation she experienced 5-10 attacks per day.

She was on sodium valproate, carbamazepine and levetiracetam. Still the seizure was poorly controlled. Her mile stone of development was normal up to 6 years of age except she had mild mental retardation. There was no family history of Epilepsy. Patient is apathetic, non-communicating initially. There was no focal weakness. Superficial and deep tendon reflexes were normal. MRI revealed a band of grey matter located deep to, and roughly paralleling, the cortex, with pachygyric overlying cortex. The band of abnormal grey matter is complete. There is posterior predilection. EEG revealed bi-frontal intermittent rhythmic delta activity. We gradually discontinue carbamazepine, built up the doses of sodium valproate and add Clobazam. After 15 days her seizure was fully controlled. She began to speak and communicate.

1. Dr. Reaz Mahmud, Assistant Professor, Department of Neurology, Dhaka medical College.

2. Kazi Mohammad Gias Uddin, Associate professor and Head, Department of Neurology, Dhaka Medical College.

3. Dr. Mohammad Aftab Rassel, MD thesis student, Department of Neurology, Dhaka medical College. 

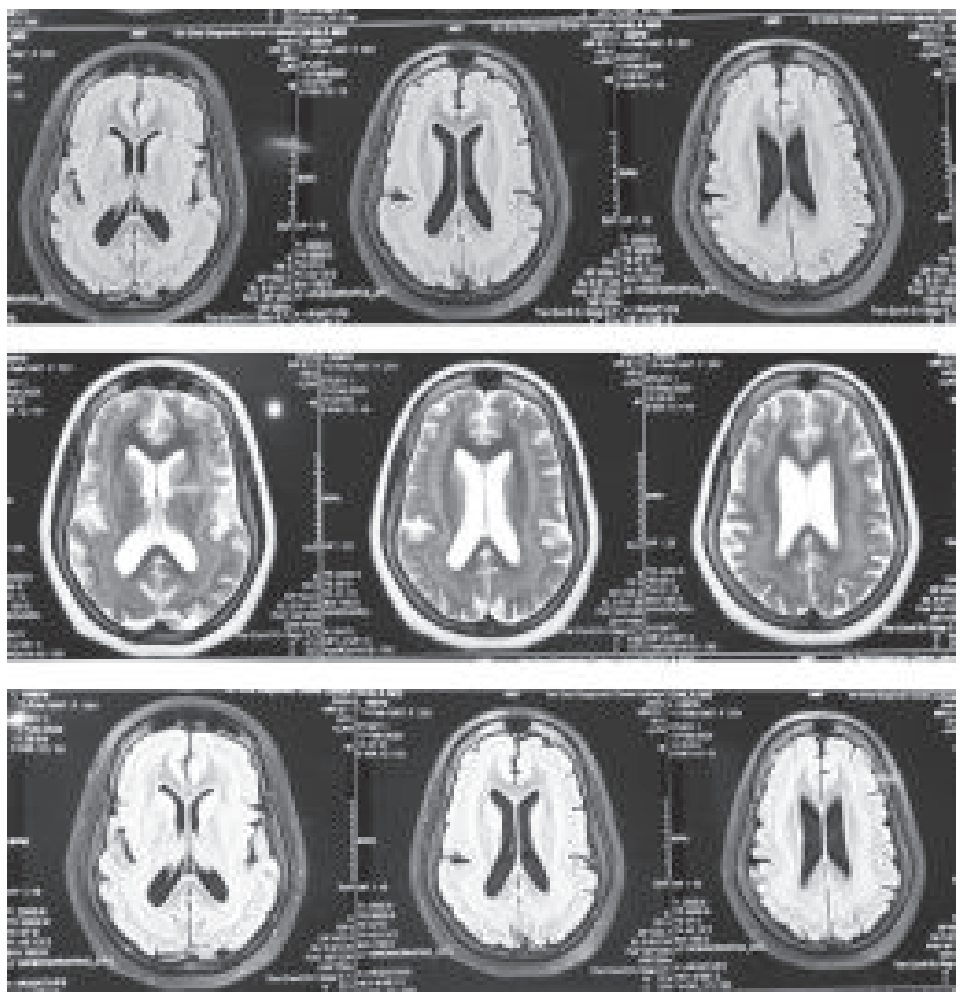

Fig.-1: MRI of Brain T1 T2 FLAIR sequence revealed a band of grey matter located deep to, and roughly paralleling, the cortex, with pachygyric overlying cortex. The band of abnormal grey matter is complete. There is posterior predilection.

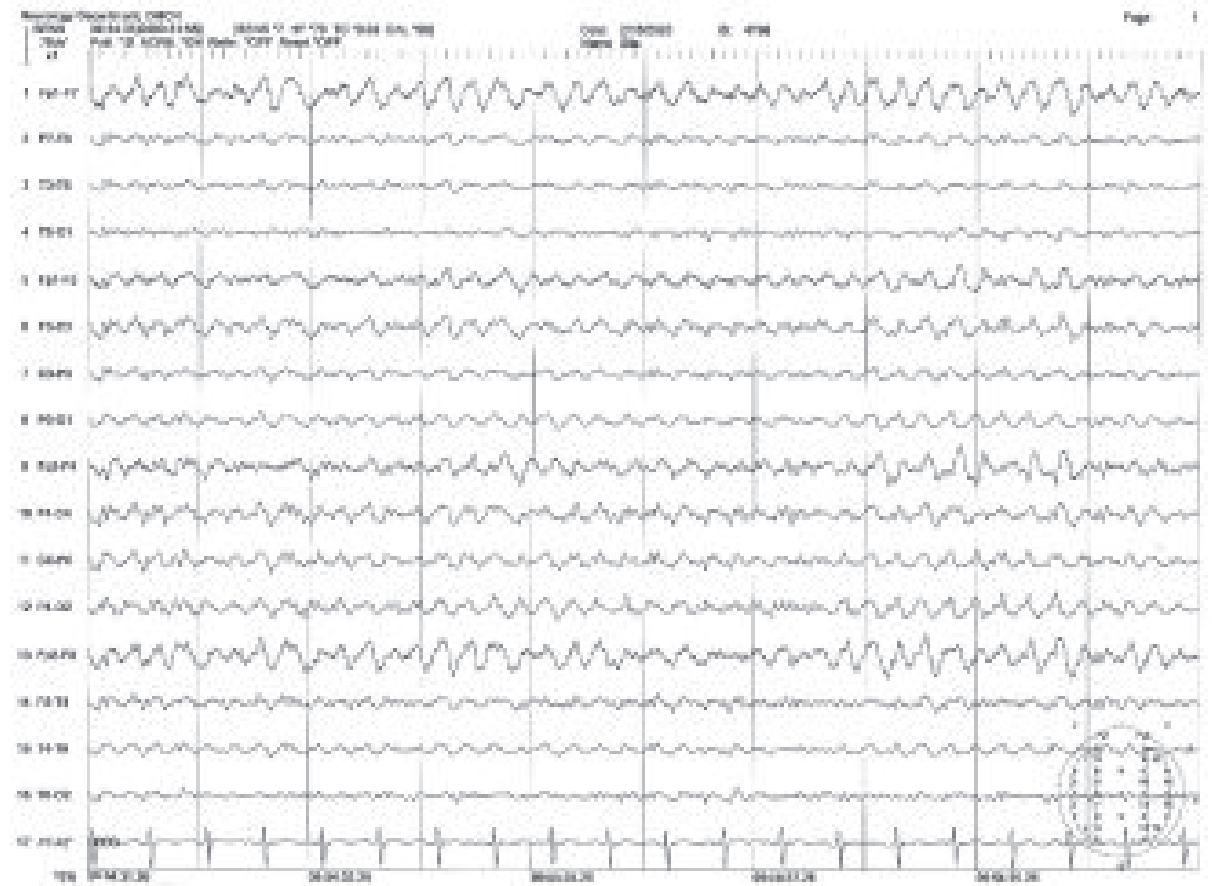

Fig.-2: EEG in bipolar montage revealed Bi-Frontal intermittent rhythmic delta. 


\section{Discussion:}

It is found that most individuals with subcortical band heterotopia have $D C X$ or LIs1gene mutations. IT is an X-linked dominant disorder. So $\mathrm{SBH}$ shows a striking skewing of sex ratio to females. As $D C X$ is carried on the $\mathrm{X}$ chromosome of males. Mutations in $D C X$ will usually have classical Lissencephaly in male whereas females have $\mathrm{SBH}^{4}$. The onset of the disease may occur at any age, predominantly in the $1^{\text {st }}$ decade but occasionally delayed until the second or third decade. ${ }^{3}$

Our patient was a female who presented at 6 years of age.

Patients with SBH will usually have mild-tomoderate intellectual disability and a mixed seizure disorder. Intellectual disability is wide with severity roughly correlating with the thickness of the heterotopic band ${ }^{3,4}$.

The seizure types are highly variable from patient to patient, and vary from focal onset seizures (partial seizures) to generalized onset seizures. Simple/complex partial seizures are most often described (68\%-69\%). Drop attacks (26\%-30\%), absence seizures (23\%-29\%), and myoclonic seizures (14\%-16\%) are frequently found alone or in combination (43\%-60\%). generalized tonic-clonic seizures fond in $19 \%-57 \%$ cases. Patients with West syndrome and Lennox-Gastaut syndrome have also been described. Importantly, a high proportion of drug resistance $(65 \%-78 \%)$ is reported, and surgical treatment yields poor outcomes. ${ }^{5,7}$.

Those with more severe MRI abnormalities have significantly earlier seizure onset and are more likely to develop Lennox-Gastaut syndrome. ${ }^{8}$

This patient presented with mild mental retardation with poorly controlled seizure. There after she also developed speech regression. So our initial diagnosis was Landau Kleffner syndrome. Carbamazepine was thought to be the factor for worsening her seizure frequency. So it was decided to gradually withdraw carbamazepine and build up the dose of sodium valproate. To rule out any secondary etiology MRI of brain with contrast was advised.
In case of SBH MRI of shows the characteristic appearance of a smoothly marginated layer of gray matter coursing parallel to the lateral ventricle, separated from the overlying cortex and under-lying ventricle by layers of white matter. Bands are nei-ther convoluted nor contiguous with the overlying cortex. They do not contain blood vessels or CSF. The thicker the band of heterotopic neurons; the worse the disability and increased prevalence of developmental delay. ${ }^{9}$

The MRI of brain of the patient revealed a typical double cortex syndrome. The thickness or her band was mild which correlate her presentation. Her EEG revealed FIRDA. Her genetic testing could not be done due unavailability of the testing facilities. In MRI there is posterior dominance, so it cold be LIS1 Mutation.

After the adjustment of the dose of the drugs her seizure was fully controlled and her speech was regained.

\section{Conclusion:}

In dealing with a patient with epilepsy syndrome or epileptic encephalopathy MRI of brain should be mandatory. Adding and adjustment of the antiepileptic drug should also be rational. We have to be careful of adding carbamazepine in this type of the patient

\section{References:}

1. Jacob H. Faktoren bei der Entstenhung der normalen und entwicklungsgestorten Hirnrinde. Z Neurol Psychiatry (Orginalien) 1936;155:1-39

2. Barkovich AJ, Jackson DE Jr. Boyer RS. Band heterotopia: A newly recognized migration anomaly. Radiology 1989; 171:455-8.

3. Palmini A, Andermann F, Aicardi J.Diffuse cortical dysplasia, or the 'double cortex syndrome':the clinical and epileptic spectrum in 10 patients. Neurology 1991;41:1656-62

4. Dobyns WB, Guerrini R, Leventer RL. Malformations of cortical development. In: Swaiman KF, Ashwal S, Ferriero DM, Schor NF, editors. Swaiman's Pediatric Neurology: Principles and Practice. ed 5. Edinburgh: Elsevier Saunders; 2012. pp. 202-231. 
5. Bahi-Buisson N, Souville I, Fourniol FJ, Toussaint A, Moores CA, Houdusse A, Lemaitre JY, Poirier K, Khalaf-Nazzal R, Hully M, Leger PL, Elie C, Boddaert N, Beldjord C, Chelly J, Francis F; SBH-LIS European Consortium. New insights into genotypephenotype correlations for the doublecortinrelated lissencephaly spectrum. Brain. 2013 Jan; 136(Pt 1):223-44. doi: 10.1093/brain/ aws323.

6. González-Morón D, Vishnopolska S, Consalvo D, Medina N, Marti M, Córdoba M, Vazquez-Dusefante C, Claverie S, RodríguezQuiroga SA, Vega P, Silva W, Kochen S, Kauffman MA. Germline and somatic mutations in cortical malformations: Molecular defects in Argentinean patients with neuronal migration disorders. PLoS One. 2017 Sep 27; 12(9):e0185103. doi: 10.1371/journal. pone. 0185103. e Collection 2017.
7. D'Agostino MD, Bernasconi A, Das S, et al. Subcortical band heterotopia $(\mathrm{SBH})$ in males: clinical, imaging and genetic findings in comparison with females. Brain. 2002; 125:2507-22.

8. Neuronal migration disorders, genetics, and epileptogenesis.Guerrini R, Filippi TJ Child Neurol. 2005 Apr; 20(4):287-99.

9. Barkovich AJ, Kjos BO. Gray matter heterotopias: MR char-acteristics and correlation with developmental and neuro-logic manifestations. Radiology 1992; 182: 493-99.

10. D'Agostino MD, Bernasconi A, Das S. et-al. Subcortical band heterotopia (SBH) in males: clinical, imaging and genetic findings in comparison with females. Brain. 2002;125 (Pt): 2507-22. 